Cadernos de

ESTUDOS LINGUÍSTIICOS - (59.2), Campinas, pp. 397-418 - mai./ago. 2017

\title{
FUNÇÃO PRAGMÁTICA DE RETORNO A TÓPICO EM ENUNCIADOS DE DUPLA NEGAÇÃO: EVIDÊNCIAS A PARTIR DE DADOS DA CIDADE DE CURITIBA
}

\author{
MARCOS GOLDNADEL* \\ (UFRGS) \\ PALOMA PETRY** \\ (UFRGS)
}

\begin{abstract}
RESUMO: O português brasileiro conta com formas alternativas para a expressão da negação sentencial. Uma dessas estruturas é a dupla negação, forma inovadora cujo uso tem aumentado de modo diverso em cada região do Brasil. Este estudo investiga as funções pragmáticas de enunciados com dupla negação encontrados em 12 entrevistas sociolinguísticas realizadas com falantes nativos da cidade de Curitiba no início da década de 90. O levantamento realizado revela que os enunciados de dupla negação foram usados para instanciar duas funções pragmáticas: denegação e retorno a tópico quantitativo.
\end{abstract}

Palavras-chave: negação sentencial, denegação, tópico sentencial

ABSTRACT: Brazilian Portuguese has alternative forms in order to express sentential negation. One such structure is the double negative sentence, an innovative form whose use has increased at different rates in each region of Brazil. This study investigates the pragmatic functions of utterances with doubled negation found in 12 sociolinguistic interviews with native speakers of Curitiba, in the early 90's. The survey carried out reveals that double negative utterances were used with two pragmatic functions: denial and return to quantitative topic.

Key words: sentential negation, denial, sentential topic

\section{INTRODUÇÃO}

Entre as tantas peculiaridades que caracterizam as variantes do português falado no Brasil está a ocorrência de enunciados de sentenças com dupla negação, como o apresentado abaixo.

(1) Não faço faculdade não.

\footnotetext{
*emegold@gmail.com

** palomapetry23@gmail.com
} 
Embora o proferimento de enunciados de sentenças como (1) não se diferenciem semanticamente de seus análogos canônicos (apenas com o operador de negação pré-verbal), passaram, nos últimos tempos, a ocorrer em quantidade significativa em diversas regiões do Brasil. Não se trata, no entanto, de um caso de variação livre. Há robusta literatura - cf. Schwegler (1991), Roncarati (1996), Furtado da Cunha (2001, 2007), Schwenter (2005, 2006), Hoeksema (2009), Van Der Auwera (2009, 2010), Seixas e Alkmin (2013), Goldnadel et al (2013), Larrivée (2010, 2011), Hansen (2009), Dahl (2001), Kiparsky e Condoravdi (2006), Detges e Valtereit (2002) - indicando que o surgimento de formas alternativas de negação reforçada, nas diversas línguas em que o fenômeno ocorre ou já ocorreu, está relacionado à expressão de funções discursivas específicas, de modo que diferenças formais em enunciados negativos semanticamente equivalentes costumam estar relacionadas a diferenças pragmáticas identificáveis.

É nessa perspectiva funcional que uma série de autores costuma atribuir a enunciados com dois operadores negativos a função de expressar ênfase. A crença de que o acréscimo de um segundo elemento com valor negativo está a serviço da manifestação de ênfase tem sido considerada adequada por uma série de estudos - Van Der Auwera (2009, 2010), Dahl (2001), Kiparsky e Condoravdi (2006) Detges e Valtereit (2002). Mais atrativa ainda essa hipótese parece quando se observa o fenômeno da dupla negação em línguas que se caracterizam por adotar como elemento negativo adicional um minimizador, como é o caso do francês. ${ }^{1}$

A ênfase, contudo, não é a única função pragmática suposta para enunciados com negação reforçada. Schwegler (1991), apesar de admitir o enfraquecimento do conteúdo pragmático de enunciados de dupla negação em português ao longo do tempo, defende a ideia de que, na variedade brasileira, esse tipo de enunciado surgiu como forma de expressar aquele tipo de pressuposição que Givón (1993) atribui a enunciados negativos de um modo geral. Dito de outro modo, o autor entende que, originalmente, enunciados de dupla negação no português brasileiro estavam a serviço de veicular atos de fala denegativos. Essa mesma hipótese é defendida de modo bastante consistente por Seixas e Alkmin (2013), com base na análise de dados do português brasileiro dos séculos XVIII e XIX.

As hipóteses de ênfase e de denegação, no entanto, têm recebido forte contestação por parte de um autor que se debruçou sobre os dados do português brasileiro. Em dois artigos hoje clássicos, ${ }^{2}$ Scott Schwenter critica a hipótese de ênfase por considerar o conceito carente de uma definição precisa. Para ele, a verificação da hipótese de que enunciados de dupla negação sejam enfáticos está na dependência de uma definição adequada do conceito de ênfase, o que, na sua opinião, ainda não foi feito com precisão suficiente. Opõe-se também à hipótese de expressão de pressuposição (no sentido givoniano), já que essa também seria uma característica de muitos enunciados com negação simples.

\footnotetext{
${ }^{1}$ Minimizadores são itens de polaridade negativa, normalmente nominais que se caracterizam por denotar quantidades muito pequenas de substâncias ou eventos de duração normalmente reduzida (que constituem partes de eventos de maior duração).

${ }^{2}$ Schwenter $(2005,2006)$.
} 
Em substituição às hipóteses que critica, Schwenter oferece a sua. Com base na análise de diversas ocorrências de enunciados negativos do português, bem como de outras línguas, defende a ideia de que enunciados com negação não canônica ${ }^{3}$ destinam-se a veicular conteúdo ativado no discurso. No caso do português, o pesquisador entende que enunciados de dupla negação ocorrem quando seu conteúdo está ativado, literal ou inferencialmente.

Embora Schwenter oponha-se às demais hipóteses, não há qualquer incompatibilidade entre ativação e ênfase ou denegação. Vale sublinhar que, enquanto a hipótese de Schwenter alude a uma função mais elementar, já que diz respeito à relação entre forma da sentença e processamento da informação configurando, a rigor, uma hipótese relativa à estrutura informacional de enunciados de dupla negação -, as demais hipóteses dizem respeito a funções retóricas, relativas, portanto, a aspectos enunciativos de caráter mais amplo. Sendo assim, nada impede, em princípio, que enunciados de dupla negação, justamente por veicularem conteúdo ativado, sejam particularmente úteis para expressar ênfase ou denegação. Na verdade, parece bastante natural esperar que enunciados enfáticos e denegativos veiculem frequentemente conteúdo discursivamente ativado. No caso da ênfase, é de se esperar que um conteúdo já proferido (ou inferível a partir de proferimento prévio), mas pouco valorizado (na opinião do enunciador), venha a ser marcado de modo enfático a partir da duplicação de elemento negativo na sentença. No caso da denegação, a ativação, mais do que provável, é certa, já que esse ato de fala depende de conteúdo contraditório previamente veiculado no discurso (de modo literal ou inferencial).

Este artigo investiga as funções retóricas de enunciados de dupla negação encontradas em entrevistas sociolinguísticas com falantes da cidade de Curitiba realizadas no início da década de $90 .{ }^{4} \mathrm{O}$ corpus escolhido tem relevância por ser representativo de uma comunidade que, segundo indica levantamento quantitativo bruto de enunciados de negação sentencial não canônica - realizado em Goldnadel et al (2013) -, ostenta uma quantidade de usos ainda pequena de enunciados de dupla negação, caracterizando-se como representativo de um ambiente que provavelmente não havia ainda assistido ao desbotamento pragmático das estruturas inovadoras. Trata-se, portanto, de uma região ideal para realizar o reconhecimento de funções pragmáticas associadas ao uso de sentenças com enunciados de negação reforçada.

$\mathrm{O}$ resultado deste estudo, com dados da cidade Curitiba, indica um uso consistente de enunciados de dupla negação para expressar denegação. Uma quantidade significativa de casos, no entanto, não parece estar a serviço dessa função. Os dados de Curitiba evidenciam a existência de uma segunda função bastante recorrente no uso de enunciados de dupla negação: retorno a tópico quantitativo. ${ }^{5}$ Essa função também pode ser identificada em entrevistas sociolionguísticas da cidade de Porto Alegre do mesmo período. Como o número

${ }^{3}$ No caso do português, o autor leva em consideração não apenas enunciados com dois operadores de negação, mas ainda aqueles em que a negação ocorre somente no final da frase.

${ }^{4}$ As entrevistas pertencem ao acervo do Projeto VARSUL.

${ }^{5}$ Cf. Goldnadel 2016. 
de ocorrências de enunciados de dupla negação é maior em Curitiba, foi possível encontrar nos dados relativos a essa cidade uma quantidade bem significativa de enunciados em que a negação reforçada serve para o retorno a tópico sentencial, ${ }^{6}$ do qual o falante se afastou em alguma medida.

Para apresentar os resultados da investigação, o artigo está organizado da seguinte forma. A seção 2 realiza uma descrição do corpus analisado. A seção 3 oferece uma caracterização das funções associadas a enunciados de dupla negação encontradas nesse corpus. Na seção 4, são apresentados os resultados quantitativos das funções instanciadas por enunciados com dupla negação no corpus investigado. A seção 5 apresenta as conclusões e direções para a pesquisa futura.

\section{METODOLOGIA E CARACTERIZAÇÃO DA AMOSTRA}

O presente estudo foi realizado a partir da análise de 12 entrevistas sociolinguísticas do banco de dados do projeto VARSUL. Todas as entrevistas consideradas foram feitas com moradores nativos da cidade de Curitiba no início dos anos 90. Como o estudo não tem pretensão de apresentar validade estatística, limitou-se a realizar uma análise quantitativa exploratória preliminar de funções pragmáticas de enunciados com dupla negação em uma quantidade limitada de entrevistas. Para essa análise, foi considerado um falante de cada tipo possível a partir da combinação das três variáveis sociais que balizaram a constituição do banco de dados do Projeto VARSUL: sexo (masculino ou feminino), idade (menos de 50 anos e mais de 50 anos) e nível de escolaridade (primário, ginásio e científico). Sendo assim, foram consideradas 12 entrevistas sociolinguísticas. Cada um dos 12 informantes considerados, então, caracteriza-se por uma das combinações apresentadas a seguir.

- sexo masculino, menos de 50 anos de idade, grau de instrução primário

- sexo feminino, menos de 50 anos de idade, grau de instrução primário

- sexo masculino, mais de 50 anos de idade, grau de instrução primário

- sexo feminino, mais de 50 anos de idade, grau de instrução primário

- sexo masculino, menos de 50 anos de idade, grau de instrução ginasial

- sexo feminino, menos de 50 anos de idade, grau de instrução ginasial

- sexo masculino, mais de 50 anos de idade, grau de instrução ginasial

- sexo feminino, mais de 50 anos de idade, grau de instrução ginasial

- sexo masculino, menos de 50 anos de idade, grau de instrução científico

- sexo feminino, menos de 50 anos de idade, grau de instrução científico

- sexo masculino, mais de 50 anos de idade, grau de instrução científico

- sexo feminino, mais de 50 anos de idade, grau de instrução científico

${ }^{6} \mathrm{O}$ conceito de tópico sentencial adotado neste estudo é apresentado na seção 3.2. 
De todas as 12 entrevistas não apenas foram extraídos os enunciados de dupla negação, como também os contextos em que ocorreram, de modo que se pode verificar, a partir da análise desses contextos, a função pragmática em cada caso. Registrou-se ainda a função sintática de cada uma das orações com dupla negação recolhidas, de modo a permitir a reflexão sobre qualquer tipo de favorecimento de ordem sintática ao uso de enunciados com negação não canônica.

\section{DUAS FUNÇÕES PRAGMÁTICAS DE ENUNCIADOS DE DUPLA NEGAÇÃO: DENEGAÇÃO E RETORNO A TÓPICO QUANTITATIVO}

Como, nos dados a serem apresentados na seção 4, as duplas negações se dividiram majoritariamente entre as funções pragmáticas de denegação e retorno a tópico quantitativo, esta seção destina-se a propor definições mais precisas para essas duas funções. Enquanto a seção 3.1 destina-se a apresentar uma breve caracterização do ato de fala de denegar, a seção 3.1.1 apresenta alguns casos de enunciados com dupla negação encontrados nas entrevistas sociolinguísticas de Curitiba em que parece evidente a instanciação de uma função de denegação. A seção 3.2, por sua vez, identifica a função de retorno a tópico quantitativo, ao que se segue, na seção 3.2.1, a apresentação de casos nas entrevistas sociolinguísticas de Curitiba em que a dupla negação realiza essa função.

\subsection{O ato de fala de denegar}

Embora o termo denegação apareça em alguns autores (Teixeira de Sousa, 2011; Cavalcanti,2012) que têm se dedicado ao estudo da dupla negação em português, também é comum encontrar essa função referida pelo termo de negação pressuposicional ou negação por pressuposição (Schwegler, 1991; Seixas e Alkmin, 2013). A rigor, todos esses termos, quando presentes na literatura sobre dupla negação sentencial, referem-se a um mesmo fenômeno. Os autores que recorrem ao termo pressuposição, Schwegler e Seixas e Alkmin, remetem ao pensamento de Givón (cf. Givón, 1993), para quem enunciados negativos frequentemente pressupõem um contexto que inclui proposição contraditória àquela por eles expressa. Nessa perspectiva, uma criança que diga "Eu não toquei no bolo", normalmente estará a pressupor que alguém tenha dito ou sugerido que ela tenha tocado.

Os termos negação pressuposicional ou negação por pressuposição, no entanto, devem ser evitados. Pressuposição é um tópico clássico da literatura pragmática, e o termo tem sido caracterizado de um modo distinto daquele proposto por Givón para a análise de enunciados negativos. Enquanto a pressuposição givoniana (associada ao uso de enunciados negativos) diz respeito à existência de desacordo entre interlocutores, a pressuposição clássica diz respeito justamente ao contrário: à situação em que determinado conteúdo é compartilhado pelos interlocutores. Por outro lado, o termo denegação, que remete à teoria dos atos de fala, parece bastante apropriado, uma vez que muitos enunciados negativos parecem justamente estar a serviço da expressão de um ato destinado a registrar o desacordo entre interlocutores. 
Nem todo enunciado com negação sentencial, no entanto, é a expressão do ato de denegar. Em primeiro lugar, dificilmente uma denegação será veiculada por conteúdo presente em oração subordinada. Na enunciação de uma sentença como (2), por exemplo, dificilmente o conteúdo da subordinada adverbial vai caracterizar um enunciado como uma denegação.

(2) Quando não me alimento bem, fico tonto.

Do mesmo modo, a ocorrência de uma oração principal com negação sentencial também não é garantia da expressão de um ato de fala de denegação.

(3) Quando me alimento bem, não fico tonto.

A enunciação de uma sentença como (3) pode constituir ou não um ato de fala denegativo. Para que se chegue a alguma conclusão a esse respeito, é necessário analisar o enunciado em seu contexto.

Em uma perspectiva particular, a Teoria Polifônica da Enunciação, Ducrot (1988) reconhece uma função recorrente associada a enunciados negativos, assumindo que enunciar uma sentença negativa é o mesmo que dar voz a outro enunciador. O exemplo (4), do autor, é bastante convincente.

(4) João não veio, ao contrário, ficou em casa.

Para Ducrot, a presença da expressão "ao contrário" em um enunciado como (4) é marca explícita da presença de outro enunciador. Como ficar em casa não é o contrário de não vir, a expressão entre vírgulas, neste caso, só pode estar a serviço de tornar manifesta a existência de interlocução. Ou seja, a expressão "ao contrário" só pode querer dizer algo como "ao contrário do que você pensa".

Kamp; Reyle (1993) também admitem o ato de fala de denegar, como se observa na passagem a seguir. ${ }^{7}$

Entre os vários outros atos de fala há um que nem sempre é distinguido da asserção e que, evidentemente, tem uma associação muito próxima com ela. É a denegação. A situação paradigmática em que a denegação ocorre é aquela em que o receptor entende o que é dito a ele, rejeita e deixa isso ser percebido pelo falante

$[\ldots]$

Em todos esses casos, o efeito da denegação é repudiar algo que foi posto tentativamente ou confidentemente por alguma outra pessoa; é rejeitar, como a presente teoria sugere, o 'quadro' que o outro falante apresentou como certo ou possivelmente correto.

(Kamp; Reyle, 1993, p. 100)

\footnotetext{
${ }^{7}$ No original: "Among the various other speech act types there is one which is not always distinguished from assertions, and which evidently has close affiliations with it. This is denial. The paradigmatic situation in which denials occur is that where the recipient understands what is said to him, rejects it, an lets that be known to the speaker. [...] In all these cases the effect of the denial is to repudiate something that has been put forward tentatively or confidently by someone else; it is to reject, as the present theory suggests, the 'picture' which the previous speaker has presented as certainly or possibly correct."
} 
Nessa perspectiva, denegação é um ato de fala que se caracteriza pela recusa daquilo que, nas palavras de Kamp e Reyle, outro interlocutor apresenta como certo ou possivelmente correto.

Givón (1993) - que também reconhece a denegação como um ato de fala particular (distinto da asserção) - vai além de Kamp \& Reyle ao admitir que um enunciado negativo pode contradizer aquilo que seu próprio enunciador afirma ou alude em porção de discurso precedente. $\mathrm{O}$ autor sugere ainda que o conteúdo de uma denegação não se opõe necessariamente a conteúdo veiculado de modo literal, como se depreende da passagem a seguir. ${ }^{8}$

Uma asserção negativa é realizada de fato com base na suposição tácita de que o ouvinte ouviu, acredita, está inclinado a tomar como certa ou ao menos está familiarizado com a proposição afirmativa correspondente.

(Givón 1993, p. 189)

Ou seja, para Givón a denegação pode dirigir-se contra conteúdo veiculado pelo interlocutor ou pelo próprio falante, de modo explícito ou não. Givón (1993) não chega a apresentar muitos exemplos de negação de conteúdo não explícito, limitando-se a mencionar um caso em que a negação se dirige contra uma pressuposição dos falantes.

A concepção de denegação adotada neste trabalho aproxima-se da encontrada em Givón. Assim como para esse autor, assume-se que um enunciado denegativo pode tomar como antecedente tanto um conteúdo presente em enunciado de interlocutor quanto em enunciado proferido pelo próprio falante. Ainda na mesma linha, admite-se denegação de conteúdo inferível de enunciado precedente, podendo ser a inferência de natureza semântica ou pragmática. Sendo assim, uma denegação pode dirigir-se contra um acarretamento, uma pressuposição semântica, uma implicatura ou simplesmente uma sugestão de definição incerta.

Outro ponto importante a salientar é que a presente abordagem, na falta de elementos para definir de modo inequívoco os limites de um enunciado, ${ }^{9}$ admite a presença de denegações em porções de texto que, em princípio, não chegam a constituir enunciado autônomo, como ocorre nos proferimentos de sentenças adversativas, como (5).

(5) Fui a Paris, mas não visitei a Torre Eifel.

Em (5), assume-se que o conteúdo da adversativa tenha um caráter denegatório, opondo-se a uma provável inferência a partir do conteúdo expresso na primeira oração, mesmo que se assuma que a adversativa, por si só, não constitui enunciado autônomo.

\footnotetext{
${ }^{8}$ No original: "A negative assertion is indeed made on the tacit assumption that the hearer either has heard about, believes in, is likely to take for granted, or is at least familiar with the corresponding affirmative proposition."

${ }^{9}$ Quem analisa fala espontânea normalmente se defronta com a dificuldade de estabelecer limites entre enunciados.
} 


\subsubsection{Dupla negação denegativa na década de 90 em Curitiba}

Entre os enunciados com dupla negação nas 12 entrevistas da cidade de Curitiba que formam o corpus deste estudo, há uma quantidade significativa de casos de uso denegativo. Encontraram-se denegações de todos os tipos mencionados: denegação de conteúdo literalmente veiculado pelo interlocutor, denegação de conteúdo inferível a partir de conteúdos veiculados pelo interlocutor, denegação de conteúdo inferível a partir de conteúdos veiculados pelo próprio falante e denegação de conteúdo literalmente veiculado pelo próprio falante. ${ }^{10}$

No exemplo a seguir, o enunciado em destaque é uma dupla negação de claro valor denegativo, que se opõe a conteúdo literalmente expresso pelo interlocutor.

(6) E: Onde é que você trabalha?

F: Trabalho na Champs de Bleu.

E: Que é que é isso?

F: É confeitaria.

E: Oh! Que chique! Tu és confeiteira?

F: Não, auxiliar de confeiteira. Por enquanto, né? Tenho esperança de chegar lá em cima ainda.

E: Mas deve ter uma mão boa.

F: Ahn?

E: Deve ter uma mão boa.

\section{F: Eu não tenho não.}

E: Mas aprende. É humilde, né? Não reconhece. E o que é que fazem lá de gostoso?

F: Ih! A gente faz tanta coisa. Eu ainda não aprendi, né? Que faz poucos dias que eu estou lá ainda, né? Não faz muito tempo. Então não aprendi tudo ainda, né? Eles fazem bolo, fazem pão, fazem-né? Tudo que é tipo de docinho, salgadinho, né?

Todas essas coisas aí eles fazem.

Interessante notar que, na fala da entrevistada que sucede aquela em que aparece a dupla negação, aparecem outros dois enunciados negativos. Em nenhum destes casos, no entanto, há qualquer motivação para a ocorrência de denegação.

Em (7), a denegação é de um conteúdo inferível a partir de informações que aparecem desde muito cedo na entrevista. Ocorre que, já no início da conversa, o entrevistador revela ter morado no bairro do entrevistado durante uma fase de sua vida. A partir de então, o entrevistado passa a ser estimulado a falar sobre elementos do bairro aludidos pelo entrevistador, que, desse modo, revela conhecimento prévio

${ }^{10}$ Embora o último tipo de enunciado denegativo seja altamente improvável, pode eventualmente ocorrer, como revela um dos exemplos a seguir. 
de muitas questões relativas ao bairro. Há, portanto, uma expectativa de que o entrevistador conheça todos os elementos mencionados pelo entrevistado. Quando o entrevistado fala de uma praça que o entrevistador desconhece, este usa a dupla negação para rejeitar a ideia de que essa praça, assim como os demais elementos anterirmente aludidos, existisse no tempo em que ali morava.

(7) E: Deixa eu ver, que mais tem no bairro. Igreja ali no centro? Você vai muito?

F: A pracinha ali em cima, né? também.

E: Não conheço essa praça.

F: Tem uma pracinha ali em cima que eles fizeram. Era um...

E: Não é do meu tempo não.

O caso a seguir contém uma dupla negação que denega conteúdo literalmente expresso pelo próprio falante em enunciado prévio. Trata-se de um diálogo em que o entrevistado está mostrando um álbum de fotos para o entrevistador e tentando identificar quem são as pessoas retratadas.

(8) F: Ih! A praia sim. Isso aqui eu nem sei o que que é. Se é uma mulher se enforcando na árvore. O que que é?

E: Näo, está com três crianças.

I: O que que está escrito aqui? A senhora quer trocar a letra!

F: Olhe como é que eu estou de cabeça baixa. Quer ver. Ah, mas essa aí é a Noeli Yada.

I: Que nome bobo é esse!

F: Não, essa não é a Noeli, não. Essa aí é a Dilma. Eu acho que é o telefone de alguém que eu peguei e pus aí atrás, tá! Essa aqui é uma sobrinha que já é morta. E essa, amiga dela.

E: Nossa! Que bonita que ela era.

Como se pode perceber, em um primeiro momento, a falante identifica uma pessoa de uma das fotos como Noeli Yada (enunciado sublinhado). Em seguida, percebe que se equivocou em sua identificação e faz uma retificação com a dupla negação, rejeitando o conteúdo literal de um enunciado anterior seu.

Em (9), o falante denega um conteúdo que parece considerar uma inferência possível a partir do que diz previamente.

(9) E: Bom, o Senhor falou que trabalhou a vida toda contrariado daí. Mas é... como tesoureiro da da da DR, é, não foi importante o Senhor ter feito Contabilidade, que daí... 
F: Bom, ajudou, é lógico, porque você vê quem trabalha com dinheiro tem que saber fazer o livro-caixa, tudo, né? Quer dizer, ajudou, lógico, né? Mas não é que fosse uma função que precisasse ser contador, né? Não precisava não. Uma pessoa ser contador na época [tinha que]- [que]- precisava cursar um Ginásio ou era só [com]com-Ah! tinha que ter o Ginásio pra daí fazer o que era considerado o científico, né? Equivalente ao Científico. Não precisava fazer.

Nessa passagem, o entrevistado começa concordando com o entrevistador ao admitir que a formação em contabilidade tenha ajudado em seu trabalho. Em seguida, no entanto, trata de desencorajar a possível conclusão de que uma formação em contabilidade fosse necessária para exercer a sua função. Uma de suas estratégias é usar a dupla negação com função denegativa.

Esses são alguns dos casos de uso de dupla negação com função denegativa encontrados, apresentados aqui como uma ilustração dos 22 casos em que essa função foi identificada entre os 50 casos de dupla negação encontrados no corpus em análise.

\subsection{A função de retorno a tópico quantitativo}

A literatura relativa ao ramo da Pragmática que hoje costuma ser identificado pelo termo Teoria da Informação é vítima de uma reconhecida polissemia terminológica. Termos como tópico e foco, por exemplo, podem receber definições tão díspares que a sua menção em um trabalho exige alguns esclarecimentos. $\mathrm{O}$ conceito de tópico usado neste trabalho (com a finalidade de colaborar para a descrição de uma função discursiva) é aquele encontrado em uma série de estudos realizados por van Kuppevelt na década de 90.

Van Kuppevelt - cf. Van Kuppevel (1995a, 1995b, 1996) - elabora uma teoria destinada a oferecer recursos para a descrição do modo como se desenrola o discurso verbal, baseada nas noções de tópico discursivo e tópico sentencial. Para o autor, o tópico discursivo pode ser depreendido de um trecho de texto (falado ou escrito) constituído por uma série enunciados com tópicos sentenciais relacionados entre si. O tópico discursivo costuma ser introduzido no discurso por um feeder, um enunciado destinado a inserir no campo do discurso uma série de indeterminações. Essas indeterminações assumem a forma de tópicos sentenciais, fundamentalmente, questões relacionadas ao tópico discursivo cujas respostas consistem em comentários expressos na forma de enunciados. No exemplo a seguir, traduzido livremente de Van Kuppevelt (1995a), o primeiro enunciado do falante A é o feeder. A partir daí, todos os enunciados do falante B são tópicos sentenciais explícitos ${ }^{11}$ (questões explícitas) e todos os enunciados do falante A são comentários (respostas) a esses tópicos. O conjunto de todos os comentários aos tópicos sentenciais constitui o tópico discursivo.

11 Tópicos sentenciais podem ser explícitos ou implícitos. Tópicos explícitos são aqueles efetivamente verbalizados ao longo da interlocução; tópicos implícitos são aqueles que supostos, no processo de interlocução, como motivos para a enunciação dos comentários. 
(10) A: - Ontem um júri de investigação chegou à conclusão de que 31 vítimas do incêndio na estação de metrô da King's Cross London morreram em consequência de um acidente e não de uma negligência

B: - Como as pessoas reagiram a essa investigação?

A: - Os parentes das vítimas a rejeitaram.

B: - Por quê?

A: - Eles acham que o júri não fez bem os seu trabalho.

B: - E qual é a consequência dessa conclusão?

A: - Agora novos processos contra os funcionários da Empresa de Transporte Regional de Londres estão fora de cogitação.

$\mathrm{O}$ primeiro enunciado, proferido pelo falante $\mathrm{A}$, é o feeder. É ele o responsável por permitir o desenvolvimento de um tópico discursivo de modo coerente, organizado a partir de uma sequência de tópicos sentenciais, estabelecidos por todas as falas de B, e de comentários, executados por todas as falas seguintes de A. ${ }^{12}$ Neste caso em análise, todas as questões expressas de modo explícito pelo falante B solicitam mais informação nova em torno do tópico discursivo estabelecido, razão pela qual van Kuppevelt as batiza de questões quantitativas.

Van Kuppevelt prevê ainda, em seu quadro conceitual, a possibilidade de haver questões qualitativas. Esse tipo de questão constitui tópico de natureza distinta, característico de situações em que o conteúdo do comentário serve de apoio a comentário precedente para torná-lo mais específico ou aceitável. Um bom exemplo é (11), traduzido livremente de van Kuppevelt (1196).

(11) A: - O que seria um bom presente de aniversário para o Harry?

B: - Uma chave inglesa.

A: - Por quê?

B: - Ele recentemente me pediu uma emprestada.

Neste diálogo, a segunda fala de B é um comentário qualitativo; serve para dar suporte à opinião expressa no enunciado precedente do mesmo falante. Comentários qualitativos são muito comuns na fala cotidiana, mesmo quando não são explicitamente solicitados por interlocutores. Uma leitura rápida de registros de fala espontânea é suficiente para revelar que, em suas interações,

${ }^{12}$ É importante sublinhar que todas as questões constituidoras de tópico - neste caso, todas as falas de $\mathrm{B}$ - podem ser apagadas sem qualquer prejuízo à continuidade tópica do discurso. $\mathrm{O}$ resultado, é claro, não é mais um diálogo, mas a fala contínua de apenas uma pessoa, como se pode ver em (i).

(i) A: - Ontem um júri de investigação chegou à conclusão de que 31 vítimas do incêndio na estação de metrô da King's Cross London morreram em consequência de um acidente e não de uma negligência. Os parentes das vítimas a rejeitaram. Eles acham que o júri não fez bem os seu trabalho. Agora novos processos contra os funcionários da Empresa de Transporte Regional de Londres estão fora de cogitação. 
falantes produzem uma quantidade significativa de comentários qualitativos, preenchendo, às vezes, uma espaço até maior do que aquele ocupado por comentários quantitativos.

Comentários qualitativos, diferentemente, dos quantitativos, não fazem o discurso avançar. Mesmo assim, em interações mais descontraídas, eles costumam ocupar extensões de fala significativas para dar suporte a opiniões emitidas, como na passagem a seguir, extraída de uma entrevista sociolinguística do acervo do Projeto VARSUL, realizada com um morador Curitiba.

(12) E: - E diante disso aqui ... Eu não sei, eu não conheço tão bem o bairro, mas como é que é servido o bairro, por exemplo, de praças esportivas, locais assim pra crianças e adolescentes mesmo?

F: - Eu acredito que está bom, viu? Porque nós temos aqui eu acredito umas oito praças esportivas nessa região aqui. Nós temos a Praça ali de Santa Rita, nós temos a praça em frente ao campo do Caxias, nós temos aqui no terminal do Vila Hauer, nós temos lá na passarela, nós temos um próximo do... na Empresa de Correio, nós temos ali em cima no Carmo também. Então eu acho que dentro de, de aqui inclusive, aqui em baixo, perto do rio, também tem mais uma. Eu acho que em termos de praça esportiva está muito bom o bairro.

Nessa passagem, o entrevistador, em sua fala, cria um tópico sentencial, uma questão a ser respondida pelo entrevistado. Mais especificamente, o entrevistador solicita do entrevistado sua opinião relativa à existência de praças esportivas no bairro. O entrevistado satisfaz a questão estabelecida pelo tópico já em seu primeiro enunciado. Todos os demais enunciados, com exceção do último, constituem comentários qualitativos à opinião presente no primeiro enunciado. São apenas ideias destinadas a dar suporte à opinião já expressa. Note-se, no entanto, que o último enunciado é uma repetição do conteúdo do primeiro, sendo, portanto, a repetição do comentário quantitativo. Essa repetição nada mais é que um retorno ao tópico sentencial (quantitativo) estabelecido, neste caso, pelo entrevistador. Esse tipo de comentário, que constitui um retorno ao tópico sentencial quantitativo, tem um caráter organizacional: colabora para a determinação daquilo que, entre todos os enunciados expressos pelo falante, deve ser considerado o foco de atenção dos interlocutores. Comentários como esse, que, depois de uma sequência de comentários qualitativos, repetem - às vezes com pequenas diferenças comentário quantitativo anteriormente expresso, cumprem a função aqui batizada de função de retorno a tópico quantitativo.

Como se pode ver, essa função de retorno a tópico quantitativo precisa ser instanciada por enunciado com sentido equivalente ao de outro enunciado, anteriormente proferido, que já satisfez à demanda estabelecida pelo tópico sentencial. Esse retorno costuma ocorrer fundamentalmente depois que o falante, por razões que lhe pareceram apropriadas, fez seguir ao comentário quantitativo inicial uma série de comentários qualitativos, normalmente destinados a justificar a adesão à ideia veiculada por esse comentário quantitativo previamente proferido. Esse retorno pode ocorrer em meio ou fim de turno. Nos dois casos, serve como uma lembrança, como uma espécie de norte para que o interlocutor não perca de vista o ponto sobre o qual o falante discorre. 


\subsubsection{Dupla negação com função de retorno a tópico quantitativo na década de 90 em Curitiba}

Enunciados com a função de retorno a tópico quantitativo podem ser afirmativos ou negativos. A observação de casos dupla negação em entrevistas do VARSUL da cidade de Curitiba revela que boa parte dos enunciados em que essas duplas negações aparecem cumpre a função de retorno a tópico quantitativo. Em alguns casos, o retorno aparece no final do turno, após uma série de justificativas ao comentário quantitativo inicial, como se observa em (13).

(13) E: As pessoas não têm reclamado, assim...

F: Não, é porque, geralmente, né? Há tempos atrás se dizia: "Não, que se sair daqui tem que ir lá pra São Lucas, no Evangélico, Hospital de Clínicas, né? Hoje não, hoje o pessoal parece que se acomodou, quer dizer, não é que se acomodou, é que a facilidade chegou, né? Então, se você precisa hoje de uma consulta, você vai no Hospital, ali você é atendido, né? Hoje também houve, pelo menos isso, é? Pela parte do INPS não existe mais aquela burocracia que você tem que ter carteira, você tem que estar revalidando, é? Hoje você precisa apresentar apenas o documento, qualquer coisa, você é bem atendido. É pelo menos atendido, não digo bem. No INPS, né? É, então isso aí facilitou, por que muita gente pudesse ser atendido em qualquer parte, em qualquer hospital desde que tenha convênio. Então, a gente não tem visto queixas, não tem ouvido queixa nenhuma não.

Em (13), ocorre inicialmente a negação simples, seguida da dupla negação. Há casos, no entanto, em que há um comentário afirmativo que promove o retorno ao tópico quantitavo e que é seguido de um enunciado com dupla negação realizando a mesma função.

(14) E: Uma vez que o senhor trabalha com comércio e tal, como é que o senhor vê a situação hoje aí dessa política, esses planos econômicos? O que que...

F: É isso aí hoje já está mais normal, já tá voltando à normalidade. Mas no primeiro mês do programa do governo novo... é... atrapalhou bastante, em função da retenção dos cruzeiros, né, do dinheiro, dos cruzados aliás, né? E... então o pessoal ficou sem dinheiro e sem opção de compra. Quer dizer... Sem opção de nada. Todo mundo ficou assustado até certo ponto, né? Então o mês de março e o princípio de abril realmente foi muito... muito duro, foi difícil. Mas não foi só pra mim, né, não foi só pra nós do comércio, foi pra todos, né. Então todo mundo se abraçou nessa hora e realmente procurou seguir em frente. E depois já aí no mês de maio já melhorou, mês de junho já tá razoável, né. E a gente vai ver como é que fica pra frente. Em termos de plano, a princípio tá dando até certo o resultado. A gente está vendo que não tá tão ruim como se pensava no começo. Desde que seja honesto realmente, né? Que devolva aquele dinheirinho que ficou lá. Mas em termos de governo, eu acho tá bom. O pessoal não pode se queixar muito não, né? Está tendo até uma estabilidade, quer dizer, com a liberação dos preços como foram feitos agora, ainda está se conseguindo preços bons pra trabalhar. É claro que existem aqueles mais gananciosos, as fábricas mais aventureiras que estão jogando alto pra ver o que conseguem, né? 
Em (14), o enunciado inicial, sublinhado, expressa o comentário quantitativo que satisfaz ao tópico estabelecido pelo entrevistador. O retorno a esse tópico ocorre inicialmente por um enunciado afirmativo (primeiro enunciado em negrito), função que a dupla negação repete no enunciado seguinte (também em negrito). Os casos em (13) e (14), por apresentarem enunciados de dupla negação que repetem o conteúdo de enunciado imediatamente anterior, poderiam sugerir que o uso da estrutura está a serviço mesmo de expressar uma mera repetição de ideias. Há, contudo, casos em que o enunciado com dupla negação não expressa repetição de conteúdo de enunciado imediatamente anterior.

(15) F: Ai! Coisa de fresco. Isso mesmo. Eu não tenho. Eu entro em qualquer lugar. Se for preciso eu entrar falar com um doutor, eu entro e falo com o doutor. Se for preciso eu entrar numa repartição, sabe? Cada repartição, cada coisa eu sei entrar, eu sei sair, sabe? Eu não tenho esse negócio de vergonha comigo não. Se for preciso eu conversar com um mendiguinho, eu converso com aquele mendiguinho do jeito dele, sabe? Converso com ele, me ponho ali no lugar dele, faço tudo do jeitinho que ele gosta, assim de conversar. Se tiver que conversar com uma pessoa mais ou menos, eu converso com aquela pessoa do tipo que aquela pessoa- eu sei que aquela pessoa vai me entender, entendeu? Se for pra mim conversar com aquela gente mais acima um pouquinho do que eu, eu sei entrar e sair direitinho, minha filha, isso eu tenho que ter absoluta certeza, né? Mas a gente tem que ser assim.

Em (15), o tópico sobre o qual a falante tece seus comentários é o que diz respeito a ela ter vergonha de mostrar-se em público. Nos primeiros enunciados, sublinhados, ela já apresenta sua resposta. Em seguida, começa a apresentar comentários qualitativos que pretendem justificar a opinião inicialmente expressa. $\mathrm{O}$ enunciado em negrito, com dupla negação, promove o retorno ao tópico quantitativo. Já em (16), o tópico é estabelecido pelo enunciado da primeira pergunta do entrevistador. $\mathrm{O}$ entrevistado retorna a esse tópico, no final de sua segunda fala, com o enunciado com dupla negação (em negrito).

(16) E: Você gostaria de sair de Curitiba, ou você sairia se você precisasse se mudar ou você preferiria ficar morando aqui?

F: Bom, eu, se tivesse que ir, né? Fazer o que? Mas eu acho que não. Se for mudar mas pra um outro bairro assim, mas ficam em Curitiba. Eu já conheci a cidade de São Francisco, eu fui pra Santo Ângelo, Florianópolis, outras cidades assim. Mas você vai só a passeio. Eu acho que pra morar não. (...)

E: Por que que você não gostou dessas cidades e gosta mais de Curitiba?

F: Eu não sei se é porque a gente foi criado aqui, né? Então, às vezes, a gente - você vê: está úmido, de repente de manhã você sai está frio, está quente, está chovendo. Cidadezinha, né? Que todo mundo reclama. E se você vai num outro lugar, se é frio é frio, se é quente é quente, se chove só chove, né? Mas eu acho que a gente já está acostumado a levar sombrinha, a blusa e sabe? Então acho que eu não sairia não. $\mathrm{Eu}$ acho que acostumo aqui mesmo. 
Todos esses casos fazem suspeitar que, no início da década de 90, na cidade de Curitiba, enunciados de dupla negação pudessem estar a serviço de uma função pragmática bastante específica, juntamente com outras já identificadas. Essa suspeita parece se confirmar com a análise quantitativa realizada sobre as entrevistas que compõem o corpus descrito na seção 2 deste trabalho.

\section{OS DADOS DA CIDADE DE CURITIBA}

O levantamento de quantidade de usos de enunciados com dupla negação em entrevistas de Curitiba revelou uma adoção ainda incipiente dessa estrutura, se comparada à quantidade encontrada em estudos realizados na região Nordeste do Brasil (Camargos (2001), (Souza, 2004), Roncarati (1996) Furtado da Cunha (2001)). Dois falantes não usaram a estrutura. Dois falantes usaram apenas uma dupla negação; um falante usou duas; dois falantes usaram três; um falante usou quatro; um falante usou cinco; dois falantes usaram oito; um falante usou nove. Apenas esse levantamento inicial já é um indicativo da baixa adoção desse tipo de estrutura na comunidade. Ao todo, foram 48 duplas negações A tabela 1 apresenta a quantidade de duplas negações usadas por cada falante.

Tabela 1: Funções pragmáticas de enunciados com dupla negação por falante, considerando sexo (m/f), faixa etária (+50/-50) e escolaridade (primário/ginásio/científico), em entrevistas realizadas com nativos de Curitiba no início da década de 90

\begin{tabular}{|c|c|c|c|c|c|}
\hline $\mathrm{N}^{o}$ Entrev. & $\begin{array}{l}\text { Tipo de } \\
\text { informante }\end{array}$ & Denegação & $\begin{array}{c}\text { Retorno a Tópico } \\
\text { Quantitativo }\end{array}$ & Indeterminado & Total \\
\hline 13 & $\begin{array}{l}\text { Masculino, } \\
+50 \text {, primário }\end{array}$ & 1 & 0 & 4 & 5 \\
\hline 14 & $\begin{array}{l}\text { Feminino, } \\
+50 \text {, primário }\end{array}$ & 2 & 0 & 1 & 3 \\
\hline 7 & $\begin{array}{l}\text { Masculino, } \\
-50 \text {, primário }\end{array}$ & 0 & 0 & 0 & 0 \\
\hline 8 & $\begin{array}{l}\text { Feminino, } \\
-50 \text {, primário }\end{array}$ & 4 & 1 & 4 & 9 \\
\hline \multicolumn{2}{|c|}{ Subtotal Primário } & 7 & 1 & 9 & 17 \\
\hline 15 & $\begin{array}{l}\text { Masculino, } \\
+50 \text {, ginásio }\end{array}$ & 2 & 1 & 0 & 3 \\
\hline 16 & $\begin{array}{l}\text { Feminino, } \\
+50 \text {, ginásio }\end{array}$ & 2 & 0 & 0 & 2 \\
\hline 3 & $\begin{array}{l}\text { Masculino, } \\
-50, \text { superior }\end{array}$ & 3 & 2 & 3 & 8 \\
\hline 4 & $\begin{array}{l}\text { Feminino, } \\
-50 \text {, ginásio }\end{array}$ & 0 & 1 & 0 & 1 \\
\hline \multicolumn{2}{|c|}{ Subtotal Ginásio } & 7 & 4 & 3 & 14 \\
\hline 2 & $\begin{array}{l}\text { Masculino, } \\
+50 \text {, científico }\end{array}$ & 1 & 0 & 0 & 1 \\
\hline
\end{tabular}




\begin{tabular}{|c|l|c|c|c|c|}
\hline 6 & $\begin{array}{l}\text { Feminino, }-50, \\
\text { científico }\end{array}$ & 0 & 0 & 0 & 0 \\
\hline 5 & $\begin{array}{l}\text { Masculino, } \\
-50, \\
\text { científico }\end{array}$ & 2 & 6 & 0 & 8 \\
\hline 12 & $\begin{array}{l}\text { Feminino, }-50, \\
\text { científico }\end{array}$ & 2 & 2 & 0 & 4 \\
\hline \multicolumn{2}{|c|}{ Subtotal Científico } & 5 & 8 & 0 & 13 \\
\hline \multicolumn{2}{|r|}{ Total } & 19 & 13 & 12 & 44 \\
\hline
\end{tabular}

Sobre os dados da tabela 1, embora seja recomendável cautela em um estudo como este, baseado num levantamento quantitativo bruto de dados - sem tratamento estatístico -, algumas observações podem ser feitas acerca da relação entre fatores sociais e uso de estruturas de dupla negação sentencial. O projeto VARSUL fez entrevistas com pessoas de três níveis de escolaridade: primário, ginásio e científico. ${ }^{13}$ Nos três níveis de escolaridade, foi possível encontrar pelo menos um falante com uso significativo de duplas negações (entrevistas 3, 5 e 8). Entre os três níveis de escolaridade, dois apresentaram um falante que não realizou enunciado com dupla negação: o primário e o científico. Considerando o conjunto de cada grupo, constatou-se a ocorrência de 17, 14 e 13 enunciados com dupla negação entre os falantes com nível primário, ginasial e científico, respectivamente. Os dados não indicam, portanto, relação entre escolaridade e o uso da estrutura não canônica.

O levantamento feito por faixa etária, no entanto, é mais significativo. O VARSUL divide os informantes em apenas duas faixas etárias: mais de 50 anos e menos de 50 anos. Entre os falantes com mais de 50 anos, houve 14 ocorrências de negação dupla. As outras 30 ocorrências foram identificadas nas entrevistas dos falantes de menos de 50 anos. Ou seja, os falantes mais jovens usaram mais que o dobro de enunciados não canônicos de negação em relação aos mais velhos, sugerindo uma correlação importante com faixa etária. Neste caso, em que o número de duplas negações é reduzido em todas as entrevistas, ${ }^{14}$ essa diferença pode estar indicando que a região onde foram coletados os dados caracteriza-se por estar passando por um simples aumento de ocorrências de enunciados de dupla negação. A observação da tabela 2 , em que, no registro das funções pragmáticas dos enunciados de dupla negação, os resultados foram divididos em função das duas faixas etárias, revela que esse aumento é condicionado.

\footnotetext{
${ }^{13}$ Essa era a divisão do ensino escolar à época da realização das entrevistas.

${ }^{14}$ Em qualquer uma das entrevistas, a contagem, mesmo que superficial, de enunciados com negação sentencial simples revela uma quantidade brutalmente superior em relação a enunciados com dupla negação.
} 
Tabela 2: Funções pragmáticas de enunciados com dupla negação por faixa etária, em entrevistas realizadas com nativos de Curitiba no início da década de 90

\begin{tabular}{|l|c|c|c|c|}
\cline { 2 - 5 } \multicolumn{1}{c|}{} & \multicolumn{4}{c|}{ Função } \\
\cline { 2 - 5 } & Denegação & $\begin{array}{c}\text { Retorno a Tópico } \\
\text { Quantitativo }\end{array}$ & Indeterminado & Total \\
\hline-50 anos & 11 & 12 & 7 & 30 \\
\hline+50 anos & 8 & 1 & 5 & 14 \\
\hline Total & 19 & 13 & 12 & 44 \\
\hline
\end{tabular}

Como se pode ver, a função de denegação é comum às duas faixas etárias, mas a função de retorno a tópico só é realizada uma vez por falante com mais de 50 anos. Já entre os falantes com menos de 50 anos, observa-se uma divisão bastante parelha de usos. Essa diferença entre faixas etárias sugere que o uso da dupla negação com a finalidade de marcar retorno a tópico quantitativo seja uma inovação em implementação no período em que foram realizadas as entrevistas analisadas. A diferença no número ocorrências da função de retorno a tópico entre faixas etárias encontrada nessa amostra é uma primeira evidência de que na cidade de Curitiba, no início da década de 90, enunciados de dupla negação ingressavam em um novo estágio, passando a servir de veículo a uma função pragmática antes não executada pela estrutura.

Vale registrar ainda que, tendo em vista o número de enunciados de dupla negação com função denegativa entre os informantes com menos de 50 anos, a função de retorno a tópico surge como um novo uso que se acrescenta ao anterior, sem, contudo, apagá-lo. Na verdade, se consideramos Seixas e Alckmin (2013), estudo que revela usos de dupla negação com valor denegativo em quantidade significativa no século XIX, o que os dados aqui apresentados podem estar revelando para Curitiba é uma estabilização do uso denegativo em uma frequência bastante baixa (em relação a enunciados canônicos, com apenas um operador de negação), mas o surgimento de um novo uso: marcação de retorno a tópico quantitativo.

A tabela 3: apresenta o levantamento relativo à função sintática das orações com dupla negação.

\begin{tabular}{|c|c|c|c|c|}
\cline { 2 - 5 } \multicolumn{1}{c|}{} & Denegação & $\begin{array}{c}\text { Retorno a Tópico } \\
\text { Quantitativo }\end{array}$ & Indeterminado & Total \\
\hline Oração absoluta & 11 & 9 & 11 & 31 \\
\hline Oração principal & 3 & 0 & 0 & 2 \\
\hline $\begin{array}{c}\text { Oração coordenada à } \\
\text { principal (assindética) }\end{array}$ & 0 & 2 & 0 & 3 \\
\hline $\begin{array}{c}\text { Oração coordenada } \\
\text { adversativa à principal }\end{array}$ & 2 & 1 & & 4 \\
\hline
\end{tabular}




\begin{tabular}{|c|c|c|c|c|}
\hline $\begin{array}{c}\text { Oração coordenada } \\
\text { aditiva à principal }\end{array}$ & 1 & 0 & 0 & 1 \\
\hline $\begin{array}{c}\text { Oração subordinada } \\
\text { objetiva direta }\end{array}$ & 2 & 1 & 0 & 3 \\
\hline TOTAL & $\begin{array}{c}19 \\
(43 \%)\end{array}$ & $13(30 \%)$ & $12(27 \%)$ & $\begin{array}{c}44 \\
(100 \%)\end{array}$ \\
\hline
\end{tabular}

Como se pode ver, a semelhança entre os enunciados com dupla negação, independentemente da função pragmática exercida, fica por conta do ambiente sintático. Praticamente todas as ocorrências estão confinadas ao âmbito da oração principal, incluindo-se aí também as duplas negações em orações coordenadas a orações principais, já que não se encontrou um só caso de dupla negação em coordenada (assindética, aditiva ou adversativa) no interior de uma estrutura de subordinação. Nos três casos em que a dupla negação se encontra em uma subordinada, trata-se de subordinada objetiva direta complementando construção epistêmica: em todos a dupla negação é uma oração que complementa a estrutura "acho que". Trata-se, portanto, de uma subordinação formulaica, destinada apenas a modalizar aquilo que poderia ser expresso sem a subordinação, sem qualquer perda de conteúdo. Essa distribuição sintática constitui elemento que reforça a ideia de que a dupla negação é um recurso de valor fundamentalmente pragmático e expressivo, já que a oração principal costuma ser a subestrutura sentencial responsável pela veiculação de valores de natureza pragmática.

A tabela revela ainda que muitos casos de enunciados de dupla negação são de difícil classificação pragmática. É possível que, nesses casos duvidosos, estejam sendo instanciadas outras funções já mencionadas na literatura - como, por exemplo, a de pausa temática (c.f. Furtado da Cunha $(2001,2007)$ ) ou de preservação da face (cf. Roncarati (1996)). Um caso que pode ter sido motivado pela estratégia de preservação da face é o seguinte.

(17 E: Imagine o volume de dinheiro, né? Que deve ter ido. Quanto tempo mais ou menos será que levou pra construir, o senhor lembra? Uns dez anos?

F: Eu não tenho lembrança mais não. Não tenho lembrança não.

E: Puxa!

Neste caso, como a resposta é bem curta, não admitindo muitas considerações adicionais, o entrevistado pode ter usado a dupla negação para não parecer ríspido.

Há ainda, entre os casos considerados indefinidos, expressões cristalizadas, como "não é fácil não" e "casar não é casaco não" - esta última usada para falar da responsabilidade que representa o compromisso do casamento. É importante registrar que os doze casos considerados indefinidos concentraram-se em quatro entrevistas. Outras seis entrevistas apresentaram apenas casos que se enquadraram nas funções previstas, e duas entrevistas não apresentaram ocorrência de dupla negação. 
Das duas funções consideradas neste estudo, a dupla negação com função de denegação foi predominante, com $43 \%$ das ocorrências. Esses dados estão de acordo com os achados de Seixas e Alkmin (2013) em um corpus de peças de teatro, artigos de jornal e correspondências pessoais do século XIX. ${ }^{15}$ No corpus deste estudo a função de denegação também aparece claramente associada a enunciados com dupla negação.

A novidade do levantamento fica a cargo da expressão, por dupla negação, da função de retorno a tópico quantitativo, definida na seção 3.2. São 13 enunciados com dupla negação instanciando essa função, perfazendo $30 \%$ de todo os casos. Vale enfatizar ainda que, em nenhum desses casos, pode-se admitir uma função concomitante de denegação, como se pode verificar nos exemplos (13)-(16) deste trabalho. Parece, portanto, que a função mais geral, identificada por Schwenter $(2005,2006)$, a de veicular conteúdo discursivamente ativado, serviu aos falantes da cidade de Curitiba no início da década de 90 para dar expressão a mais de uma função de caráter interacional: a função de denegação e a função de retorno a tópico quantitativo.

\section{CONCLUSÃo}

A multiplicação sincrônica de formas de negação sentencial é um fenômeno amplamente atestado nas línguas. Vossen e Van der Auwera (2014) dá uma ideia da amplitude do fenômeno quando identifica, na Ásia e na Oceania, 81 línguas com dupla negação, quatro com tripla negação e uma com quádrupla negação. O fenômeno, que é amplamente conhecido em função da negação em francês, já levou a alterações diacrônicas nos padrões sentenciais de negação no inglês, no africâner, no grego, entre outras, constituindo um fenômeno que a literatura convencionou chamar de Ciclo de Jespersen. Parte da investigação relacionada ao fenômeno diz respeito à identificação das causas para o surgimento de estruturas alternativas de negação no interior de sistemas que contam com formas linguísticas bem estabelecidas.

Este trabalho procurou identificar as funções pragmáticas de enunciados de dupla negação em um corpus de entrevistas sociolinguísticas realizadas no início da década de 90 na cidade de Curitiba. A escolha do corpus decorreu do fato da cidade ser, na década de 90, uma localidade que experimentava um uso ainda incipiente da estrutura alternativa, sendo, portanto, ambiente propício para investigar as possíveis funções de enunciados de dupla negação, em virtude de os usos da nova estrutura não terem ainda se ampliado de modo a apagar sua utilidade inicial.

${ }^{15}$ Embora as autoras considerem que o século XVIII já devia apresentar a estrutura na fala, as evidências robustas de ocorrência em texto escrito são apenas do séc. XIX. 
$\mathrm{O}$ resultado obtido reforçou uma hipótese anteriormente defendida em Schwegler (1991) e Seixas e Alkmin (2013), segundo a qual enunciados com dupla negação cumprem uma função de expressar uma atitude de denegação. Identificou-se, no entanto, uma função adicional, promoção de retorno a tópico quantitativo, numericamente menos expressiva no corpus investigado, mas, mesmo assim, significativa o suficiente para fazer supor que uma estrutura alternativa de negação, no curso de sua aplicação ao longo da história de uma língua, pode assumir funções diversificadas.

Os resultados deste estudo são, no entanto, preliminares. Para reforçar a hipótese de uma nova função pragmática de enunciados com dupla negação, seria conveniente ainda fazer novos levantamentos no mesmo corpus. Uma das tarefas necessárias é verificar se a negação simples também é utilizada para promover o retorno a tópico quantitativo. Provavelmente é, já que a função de retorno a tópico se caracteriza por uma repetição de conteúdo previamente veiculado pelo falante, podendo este ser, inclusive, expresso em oração afirmativa (cf. exemplo (12)). A comparação quantitativa de enunciados com negação simples e enunciados com dupla negação executando a função de retorno a tópico, no entanto, permitirá perceber se a nova estrutura, na sincronia analisada, está assumindo uma função mais especializada, deixando para a negação simples a tarefa de expressar conteúdos negativos pragmaticamente desmarcados.

\section{$\overline{\text { BIBLIOGRAFIA }}$}

CAMARGOS, Marcelo. A negativa: uma análise qualitativa. Anais do V Congresso de Ciências Humanas, Letras e Artes, Centro de Artes e Convenções de Ouro Preto, 2001. Disponível em : $<$ http://www.ichs.ufop.br/conifes/>. Acesso 10 set. 2015.

CAVALCANTE, R. A negação pós-verbal no português brasileiro: análise descritiva e teórica de dialetos rurais de afro-descendentes. 2007. 161 f. Dissertação de Mestrado - Instituto de Letras, 2007.

DAHL, O. 2001. Infl ationary eff ects in language and elsewhere. In: BYBEE, J.; HOPPER, P. Frequency and the emergence of linguistic structure. Amsterdam/Philadelphia: John Benjamins, 2001, pp. 471-480.

DETGES, U.; WALTEREIT, R. Grammaticalization vs reanalysis: a semantic-pragmatic account of functional change in grammar. Zeitschrift fur Sprachwinssenchaft, 21.1, 2002, pp. 151-195.

DUCROT, O. Polifonia y argumentacion. Calli: Universidad Del Valle, 1988, p. 190.

FURTADO DA CUNHA, M. A. O modelo das motivações competidoras no domínio funcional da negação. DELTA 17, 2001, pp. 01-30.

FURTADO DA CUNHA, M. A. Grammaticalization of the strategies of negation in Brazilian Portuguese. Journal of Pragmatics, 39, 2007, pp. 1638-1653.

GIVÓN, T. English Grammar: a functional-based introduction. Cambridge: Cambridge, 1993, p. 296. 
GOLDNADEL, M. Funções pragmáticas de enunciados de dupla negação: análise de dados de Curitiba. ReVEL, edição especial, nº 13, 2016.

GOLDNADEL, M.; LIMA, L. S.; BREUNIG, G.; ESQUIVEL, N. A.; LUZ, J. P. Estratégias alternativas de negação sentencial na região sul do Brasil: análise da influência de fatores pragmáticos a partir de dados do projeto VARSUL. Rev. Est. Ling., v. 21, no 2, 2013, pp. 35-74.

HANSEN, M. M. Reinforcers in old and middle french: a discourse-functional approach. In: HANSEN, M. M.; VISCONTI, J. Current trends in diachronic semantics and pragmatics. Bingley: Emerald Group Publishing Limited, 2009, pp. 227-250.

HOEKSEMA, J. Jespersen recycled. In: VAN GELDEREN, E. Cyclical change. Amsterdam: John Benjamin, 2009, pp. 15-34.

KAMP, H., REYLE, U. From discourse to logic. Dordrecht: Kluwer, 1993, p. 713.

KIPARSKY, P.; CONDORAVDI, C. Tracking Jespersen's cycle. In: JANSE, M.; JOSEPH, B.D.; RALLI, A. Proceedings of the 2nd International Conference of Modern Greek Dialects and Linguistic Theory. Mytilene: Doukas, 2006, pp. 01-22.

LARRIVÉE, P. The pragmatic motifs of the Jespersen cycle: Default, activation, and the history of negation in French. Lingua, 120, 2010, pp. 2240-2258.

LARRIVÉE, P. The role of pragmatics in grammatical change: The case of French preverbal non. Journal of Pragmatics, 43, 2011, pp. 1987-1996.

RONCARATI, C. A negação no português falado. In: MACEDO, A. T.; RONCARAT, C.; MOLLICA, M. C. Variação e discurso. Rio de Janeiro: Tempo Brasileiro, 1996, pp. 97-112.

SEIXAS, V. C.; ALKMIN, M. G. R. A negação sentencial em textos de autores brasileiros dos séculos XVIII e XIX: considerações sobre implementação, transição e origem da estrutura [NãoVNão]. Veredas, v. 17, no 2, 2013, pp. 83-113.

SCHWEGLER, A. Predicate negation in contemporary Brazilian Portuguese: a change in progress. Orbis, Leuven, v. 34, pp. 187-214, 1991.

SCHWENTER, S. A. The pragmatics of negation in Brazilian Portuguese. Lingua, Amsterdam, v. 115, pp. 1427-56, 2005.

SCHWENTER, S. A. Fine-Tuning Jespersen's Cycle. In: Birner, B.; Ward, G. Drawing the Boundaries of Meaning: Neo-Gricean Studies in Pragmatics and Semantics in Honor of Laurence R. Horn. Amsterdam: Benjamins, 2006, pp. 327-344.

SOUZA, A. S.; LUCCHESI. D. Estruturas de negação em uma comunidade rural afro-brasileira. Hyperion, no 7, 2004. Disponível em : <http://www.hyperion.ufba.br/revista_7_04.htm>. Acesso em 10 set. 2015.

TEIXEIRA DE SOUSA, L. Sentential Negation in Brazilian Portuguese: Pragmatics and Syntax. JournaLIPP, 1, 2011, P. 89-103

VAN DER AUWERA, J. The Jespersen Cycles. In: VAN GELDEREN, E. Cyclical change. Amsterdam: John Benjamin, 2009, p. 35-71.

VAN DER AUWERA, J. On the diachrony of negation. In: HORN, L. The expression of negation. New York: Walter de Gruyter, 2010, p. 73-109. 
VAN KUPPEVELT, J. Discourse structure, topicality and question. Journal of Linguistics, 31, 1995a, pp. 109-147.

VAN KUPPEVELT, J. Main structure and side structure in discourse. Linguistics, 33, 1995b, pp. 809-833.

VAN KUPPEVELT, J. Directionality in Discourse: Prominence Differences in Subordination Relations. Journal of Semantics, 13, 1996, pp. 363-395.

VOSSEN, F; VAN DER AUWERA, J. The Jespersen cycles seen from Austronesian. In: HANSEN, M. B. M.; VISCONTI, J. The diachrony of negation. Amsterdam: John Benjamin, 2014, pp. 47-82. 